
В АНТРОПОГЕННОЙ СРЕДЕ ЕВРОПЕЙСКОГО СЕВЕРА РОССИИ

\author{
Андронова М.М.
}

Вологодский институт права и экономики ФСИН России, Вологда, е-таil: mary1969@yа.ru

\begin{abstract}
Зеленые насаждения населенных пунктов, являясь одним из элементов городских экосистем, выполняют различные функции по формированию и поддержанию благоприятной среды для проживания населения. Сформировавшийся в суровых природно-климатических условиях ассортимент древесных видов слишком беден для создания высокодекоративных зеленых насаждений. Безморозный период для городов области составляет 120-135 дней и часто сокращается по причине поздневесенних и раннеосенних заморозков. В сложившихся условиях одним из направлений расширения перечня пород, используемых в зеленом строительстве, является интродукция инорайонных видов, обладающих высокими адаптационными способностями. В рамках проводимых исследований на территориях малых городов Вологодской области изучены вопросы адаптации растений к новым условиям. Для оценки зимостойкости и морозоустойчивости использована методика ГБС РАН. Сделан вывод об устойчивости растений к термическим условиям. Наиболее устойчивыми являются местные виды, адаптационные способности которых развивались в ходе эволюции. Среди экстразональных видов наибольшую устойчивость имеет липа мелколистная (Tilia cordata L.). Выделены виды-интродуценты, обладающие более высокой устойчивостью, а именно: сосна скурченная (Pinus contorta Douglas ex Loudon), ель колючая (Рicea pungeus Engelm.), ива ломкая (Salix fragilis L.), сирень венгерская (Siringa josikaea Jacq. fil.), карагана древовидная (Сaragana arborescens Lam.). K наименее устойчивым к воздействию температур отнесены: каштан конский обыкновенный (Aeculus hippocastanum L.), вяз мелколистный (Ulmus parvifolia Jacq.), спиреи дубравколистная и иволистная (Spiraea chamaedryfolia L., Spiraea salicifolia L.), рябинник рябинолистный (Sorbaria sorbifolia (L.) A. Braun), жимолость татарская (Lonicera tatarica L.), для которых характерно обмерзание не только однолетних, но и более старых побегов. Кроме того, отмечено, что устойчивость видов даже в условиях Вологодской области может значительно отличаться в зависимости от зональных отличий места произрастания (подзоны южной и средней тайги).
\end{abstract}

Ключевые слова: древесные виды, зимостойкость, морозоустойчивость, индекс обмерзания, урбанизированная среда

\title{
WINTER HARDINESS AND FROST RESISTANCE OF WOOD SPECIES IN THE ANTHROPOGENIC ENVIRONMENT OF EUROPEAN NORTH OF RUSSIA
}

\author{
Andronova M.M. \\ Vologda Institute of Law and Economics of the Federal Penal Service of Russia, Vologda, \\ e-mail: mary1969@ya.ru
}

\begin{abstract}
Green plantations of settlements being one of the elements of urban ecosystems perform various functions for the formation and maintenance of an enabling environment for the population's living. Formed in severe climatic conditions the range of tree species is too poor to create highly decorative greenery. The frost-free period for the cities of the region is 120-135 days, which often changes towards reduction due to late spring and early autumn frosts. Under the current conditions one of the directions for expanding the list of species used in green construction is the introduction of non-native species with high adaptive abilities. As part of ongoing research in the small towns of the Vologda region adaptation of plants to new conditions is studied. To evaluate winter hardiness and frost resistance the methodology of the GBS of the Russian Academy of Sciences was used. A conclusion is drawn about the resistance of plants to thermal conditions. The most resistant are the native species whose adaptive abilities developed during evolution. Among extrazonal species Small-leaved linden (Tilia cordata L.) has the greatest resistance. Species-introducents with higher resistance are distinguished, namely: shore pine (Pinus contorta Douglas ex Loudon), Colorado spruce (Picea pungens Engelm.), willow brittle (Salix fragilis L.), lilac Hungarian (Syringa josikaea Jacq. fil.), Siberian peashrub (Caragana arborescens Lam.). To the least resistant to the influence of temperatures are: horse chestnut (Aesculus hippocastanum L.), Chinese elm (Ulmus parvifolia Jacq.), Germander spiraea (Spiraea chamaedryfolia L.) and Willowleaf spirea (Spiraea salicifolia L.), Rovan leaf spirea (Sorbaria sorbifolia (L.) A. Braun), Tartarian honeysuckle (Lonicera tatarica L.), which is characterized by the freezing of not only annual but also older shoots. In addition it was noted that the resistance of species even in the conditions of the Vologda region may differ significantly, depending on the zonal differences in the place of growth (subzones of the southern and middle taiga).
\end{abstract}

Keywords: wood species, winter hardiness, frost resistance, freezing index, urban environment

В конце XX века и начале нового тысячелетия в России, как и в мире в целом, приоритетными общечеловеческими ценностями признаются социальные, экологические и культурные функции леса. Все они рассматриваются во взаимосвязи с улучше- нием, а точнее сказать, с повышением биологического разнообразия, в том числе и городских зеленых насаждений.

Являясь одним из элементов урбоэкосистем, зеленые насаждения выполняют различные функции по формированию 
и поддержанию благоприятной среды для проживания населения.

Для создания архитектурно-художественной среды с высоким эстетическим восприятием элементов городского устройства необходимо предусмотреть подбор пород деревьев и кустарников таким образом, чтобы обеспечивалась долговременная декоративность и привлекательность насаждений. Для условий с суровыми природнорастительными условиями такой эффект может быть достигнут только внедрением новых, инорайонных, видов, что позволяет оптимизировать городскую среду для восприятия населения.

Успешное введение новых пород в зеленое строительство характеризуется высокой устойчивостью растений к неблагоприятным факторам среды. Одним из важнейших биологических признаков растений, позволяющих проводить их натурализацию на север, является зимостойкость. Работы по интродукции древесных растений в условия севера в последнее время проводятся достаточно широко [13]. При этом исследователями придается особое внимание оценке зимостойкости древесных видов [4-6]. Определение отношения инорайонных видов к условиям урбанизированной среды малых городов Европейского Севера и являлось одним из направлений проведенных исследований на территории Вологодской области.

Вологодская область расположена на северо-западе европейской территории России в зоне тайги. Территория области простирается с запада на восток на 700 км, а на юг распространяется лишь на 400 км.

По условиям агроклиматического зонирования территория Вологодской области подразделена на два агроклиматических района, отличающихся суммами активных температур и осадков за вегетационный период.

Для области характерны частые вторжения арктических холодных воздушных масс в любое время года, сопровождающиеся резким понижением температуры и, как следствие, возвратными заморозками, вызывающими повреждение и гибель растений.

Безморозный период в среднем длится 100-120 дней. Для городов безморозный период длится 115-135 дней в зависимости от агроклиматической зоны [7].

Устойчивый переход среднесуточной температуры воздуха через $15^{\circ} \mathrm{C}$ наблюдается во второй декаде июня. Период с температурами воздуха выше $15^{\circ} \mathrm{C}$ продолжается в течение 50-60 дней. Заморозки начинаются во второй декаде сентября, в отдельные годы - раньше (вторая - третья декада августа).

Первый снежный покров появляется в третьей декаде октября. Устойчивый снежный покров обычно появляется во второй декаде ноября. Снежный покров благодаря малой теплопроводности способствует сохранению тепла в почве, предохраняя ее от глубокого промерзания и защищая зимующие растения от вымерзания. Средняя глубина промерзания почвы за зиму составляет 50-70 см, но в отдельные годы она значительно отклоняется от средней величины и в холодные и малоснежные зимы достигает 90-120 см, нанося ущерб растениям, особенно теплолюбивым видам [7].

Ассортимент местных пород деревьев и кустарников, сформировавшийся в суровых условиях, характеризуется скудным составом. К основным лесообразующим породам относят семь видов деревьев: ель (обыкновенная и сибирская), сосна обыкновенная, береза (повислая и пушистая), осина, ольха серая. В лесах Вологодской области еще можно встретить лиственницы сибирскую и Сукачева, пихту сибирскую и сосну сибирскую кедровую, которые заходят на территорию области с севера и востока или произрастают в культуре. Липа мелколистная, дуб черешчатый, клен остролистный, вязы (гладкий и шершавый) - редкие древесные породы для лесов области, многие из них занесены в региональную Красную книгу. Количество видов кустарников в лесах области небольшое. К редким кустарникам, в частности, относится калина обыкновенная, к очень редким - свидина белая. Следовательно, и ассортимент древесно-кустарниковых пород, используемый в озеленении населенных пунктов Вологодской области, в основном представлен таежными породами деревьев и кустарников. Представители местной флоры наиболее устойчивы в условиях Севера. Они относятся к основному ассортименту и должны составлять не менее $60 \%$ в общем составе зеленых насаждений [8].

В то же время для решения задачи создания наиболее комфортных условий для проживания населения необходимо проведение работ по интродукции инорайонных видов с учетом их происхождения, возможной адаптации к местным природ- 
ным условиям, декоративности растений. В настоящее время предлагается широкий ассортимент видов-экзотов для использования в ландшафтном дизайне. Однако далеко не весь предлагаемый перечень древесных растений отвечает требованиям, предъявляемым к посадочному материалу по критериям его зимостойкости. Проблема выбора зимостойких видов деревьев и кустарников является сложной и комплексной [9].

Исследования проводились на территории малых городов Вологодской области, отличающихся природно-климатическими условиями. Оценка зимостойкости и морозоустойчивости проведена для 46 древесных видов, относящихся к различным флористическим областям. Как отмечают Р.Н. Матвеева, О.Ф. Буторова, А.Б. Романова [10], уточнение приуроченности растений к определенным физико-географическим районам с различными естественно-природными характеристиками позволяет сделать предположение о возможности интродукции вида в новые условия произрастания. И вполне естественно, что виды с широким диапазоном экологической валентности, ареалом распространения которых являются районы со сходными в первую очередь климатическими условиями, будут являться наиболее перспективными с точки зрения интродукции.

Кроме того, является хорошо известным фактом, что города - это островки с особым микроклиматом $[11,12]$. Городская застройка, особенно многоэтажная, изменяет направление потоков ветра, создавая зоны, защищаемые от высоких ветровых нагрузок, а также температурный режим территорий. Его формирование обусловлено усиленным притоком антропогенного тепла (работа промышленных предприятий, транспорт, котельные установки, а также дополнительные источники теплового излучения - искусственные покрытия улиц и площадей, крыш и стены зданий). Воздействие промышленных предприятий и транспорта, существенно изменяющих состав воздуха в направлении уменьшения содержания кислорода и увеличения концентрации углекислого газа, способствует развитию парникового эффекта, что влечет за собой повышение температуры по сравнению с окружающими территориями и увеличение безморозного периода. Это, в свою очередь, создает благоприятные условия для внедрения в городские экосистемы новых инорайонных видов.
Т. Оук [11] продемонстрировал, что даже в малых населенных пунктах с населением 1000 чел. образуются так называемые городские островки тепла, в которых температура на $2,2^{\circ} \mathrm{C}$ выше окружающей местности. Согласно формуле Оука для малых городов Вологодской области превышение температуры воздуха над окружающей местностью находится в пределах $2,71-3,39^{\circ} \mathrm{C}$.

Одним из приспособлений растений к сезонным изменениям погоды является адаптация их к термическим условиям. Активная вегетация большинства растений проходит в период со средними суточными температурами воздуха выше $+10^{\circ} \mathrm{C}$. Безморозный период для городов области составляет 115-135 дней в зависимости от агроклиматической зоны. Но в отдельные годы может значительно сокращаться поздневесенними и раннеосенними заморозками.

\section{Материалы и методы исследования}

Материал для написания данной статьи был подготовлен на основании изучения древесных растений, проведенного в период с 2012 по 2016 г. на территории малых городов Вологодской области. Оценку зимостойкости древесных растений проводили после окончания поздневесенних заморозков по шкале Главного ботанического сада Академии наук (ГБС РАН): I - растение не обмерзает; II - обмерзает не более $50 \%$ длины однолетних побегов; III - обмерзает от 50 до $100 \%$ длины однолетних побегов; IV - обмерзают не только однолетние, но и более старые побеги; V - обмерзает надземная часть до снегового покрова; VI - обмерзает вся надземная часть; VII - растение вымерзает целиком.

Для оценки морозоустойчивости древесных пород определялся индекс обмерзания и полученные данные сравнивались со следующей шкалой ГБС РАН: 0 - растение не обмерзает; 0,1-0,9 - растение слабо обмерзает; 1,0-7,9 - растение умеренно обмерзает; 8,0-69,9 - растение значительно обмерзает; 70,0-100,0 - растение полностью вымерзает. Здесь 0-100,0 - значения индекса обмерзания, \%.

Индекс обмерзания определяли по формуле

$$
И=\frac{100 \cdot L \cdot C}{H \cdot C},
$$

где $L$ - длина обмерзшей части ветки, м; $c-$ диаметр у основания обмерзшей части ветки, м; $H$ - высота растения, м; $C$ - диаметр ствола (ниже первой ветки), м. 
Результаты исследования и их обсуждение

Одним из приспособлений растений к сезонным изменениям погоды является адаптация их к термическим условиям. Активная вегетация большинства растений проходит в период со средними суточными температурами воздуха выше $+10^{\circ} \mathrm{C}$. Безморозный период для городов области составляет 115-135 дней в зависимости от агроклиматической зоны. Но в отдельные годы может значительно сокращаться поздневесенними и раннеосенними заморозками.

Зимостойкость - один из биологических признаков, определяющих возможность интродукции растений на север. Под зимостойкостью понимают устойчивость растений к длительным неблагоприятным условиям зимовки, к которым главным образом относят морозы, внезапные резкие колебания температуры, выпирание и разрыв корней ледяной прослойкой, образующейся в почве, солнечные ожоги в период ясной морозной погоды, иссушение солнцем и ветром стволов при отсутствии сокодвижения, вымокание в талой воде весной $[1,6,13]$. С другой стороны, зимостойкость растений можно рассматривать как один из параметров оценки их декоративности, поскольку она неизбежно влияет на внешний вид растений. Кроме того, представители дендрофлоры, относящиеся к сильнообмерзающим растениям, требуют дополнительных затрат на поддержание их декоративных свойств и, следовательно, эстетического восприятия насаждений в целом, что также следует учитывать при выборе пород для озеленения элементов городской структуры.

Морозоустойчивость древесных пород - это способность растений переносить длительные понижения температуры (ниже $-25^{\circ} \mathrm{C}$ ), суровые зимы, поздневесенние заморозки. У морозоустойчивых пород обычно не образуются морозобойные трещины при сильных морозах, не повреждаются весенними заморозками молодые побеги [13].

После окончания поздневесенних заморозков, в результате которых могут повредиться начавшие расти побеги, производилась оценка зимостойкости наблюдаемых деревьев и кустарников и данные показатели сравнивались с опубликованными ранее (таблица).

Находясь в сходных условиях произрастания, растения могут по-разному реагировать на неблагоприятные условия.
Наиболее зимостойки местные виды: лиственница сибирская, ель европейская, сосна обыкновенная, черемуха обыкновенная, рябина обыкновенная, шиповник майский. Самыми устойчивыми к природно-климатическим условиям Вологодской области из экстразональных видов является липа мелколистная, среди инорайонных видов сосна скрученная, ель колючая, ива ломкая, сирень венгерская, карагана древовидная. Слабо обмерзают: калина обыкновенная, свидина белая, арония черноплодная, барбарис обыкновенный, боярышник кровавокрасный, вишня обыкновенная, кизильник блестящий, дуб черешчатый, клен остролистный, тополь бальзамический, тополь серебристый, яблоня ягодная, туя западная, сосна кедровая сибирская. Самыми уязвимыми к суровым климатическим условиям из деревьев-интродуцентов являются: каштан конский обыкновенный, вяз мелколистный. Среди кустарников к этой группе можно отнести снежноягодник белый, спиреи дубравколистную и иволистную, рябинник рябинолистный, жимолость татарскую, для которых характерно обмерзание не только однолетних, но и более старых побегов. Однако здесь следует отметить, что кустарниковые формы достаточно быстро восстанавливаются после повреждения низкими температурами и поздневесенними заморозками.

При выборе видов для озеленения населенных пунктов следует учитывать и тот факт, что зимостойкость не является постоянным свойством и может изменяться год от года в зависимости от погодных условий, происхождения семян и саженцев, возраста насаждений.

Огромную роль в адаптации растений к различным природно-растительным условиям играет их место расположения в насаждениях. Наибольшее воздействие неблагоприятные климатические факторы оказывают на деревья и кустарники, произрастающие на открытых местах, подверженных более сильному влиянию резких холодных ветров и пониженных температур окружающего воздуха. Растения, особенно с ранними сроками сезонного развития, расположенные на солнечных местах, защищенных от воздействия холодных ветров, начинают вегетировать раньше растений этого же вида, находящихся в менее благоприятных условиях. Это, в свою очередь, может являться причиной повреждения их при возвратных весенних заморозках (дуб черешчатый, клен ясенелистный и др.). 


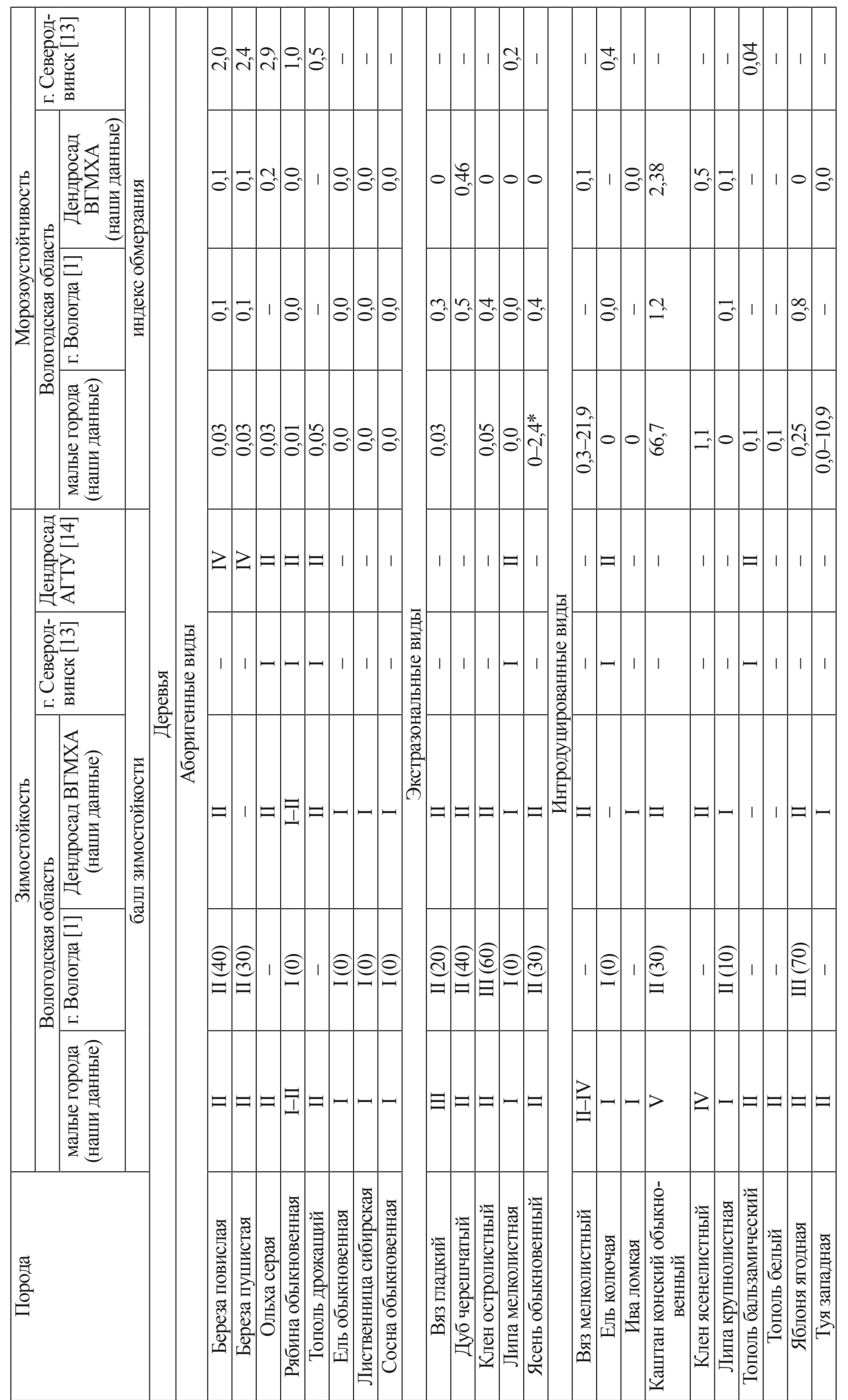

- ADVANCES IN CURRENT NATURAL SCIENCES № 5, 2018 


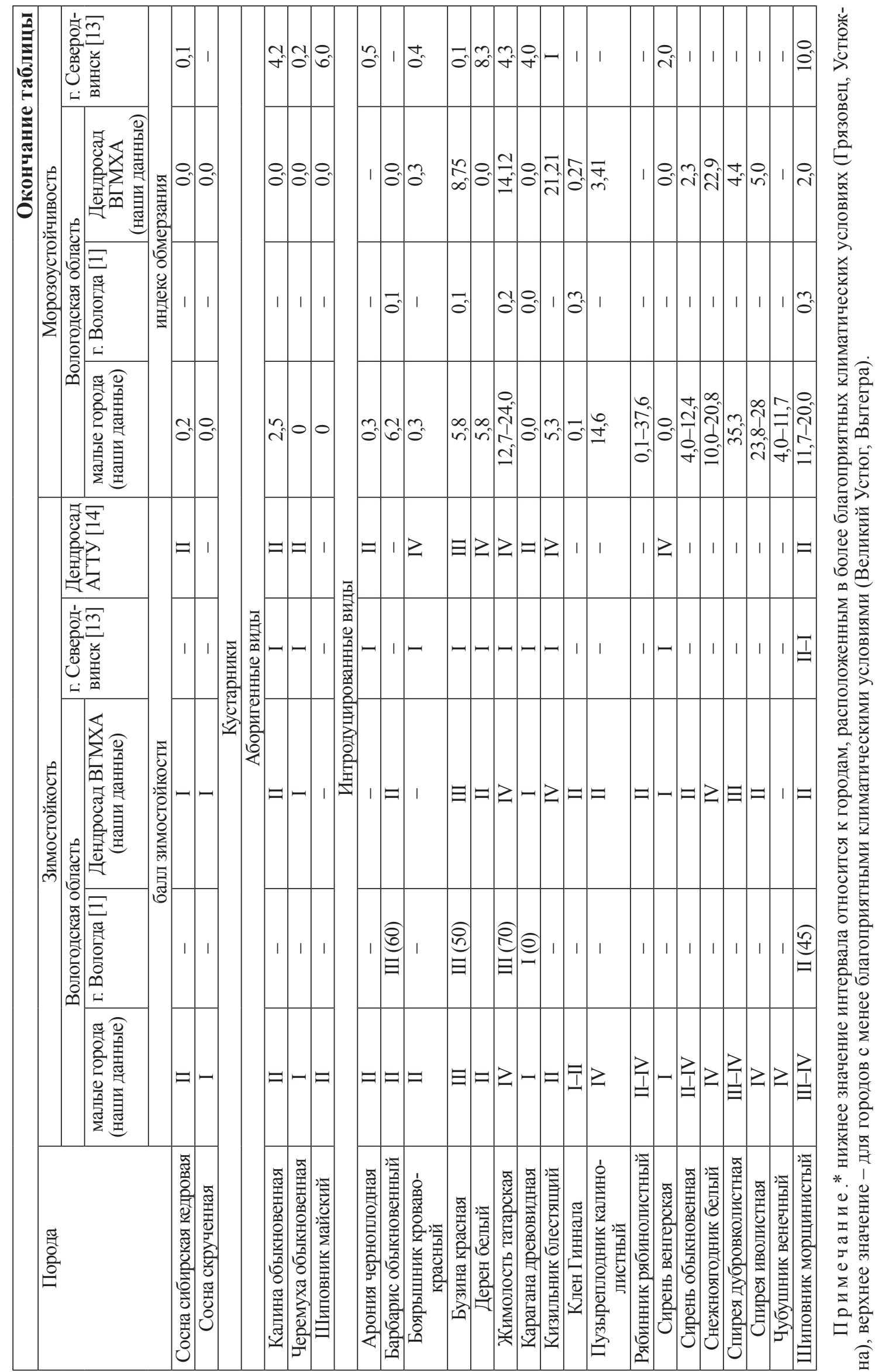

口 УСПЕХИ СОВРЕМЕННОГО ЕСТЕСТВОЗНАНИЯ № 5, 2018 


\section{Выводы}

Таким образом, зимостойкость и морозоустойчивость видов дендрофлоры является важным фактором, определяющим условия интродукции их на Европейском Севере России. Наиболее устойчивым к природноклиматическим условиям Вологодской области из экстразональных видов является липа мелколистная, а среди инорайонных видов - сосна скрученная, ель колючая, ива ломкая, сирень венгерская, карагана древовидная, что указывает на перспективность их использования в озеленении малых городов Вологодской области.

\section{Список литературы}

1. Бабич Н.А. Интродуценты и экстразональные виды в антропогенной среде (на примере г. Вологды) / Н.А. Бабич, Е.Б. Карбасникова, И.С. Долинская. - Архангельск: ИПЦ САФУ, 2012. - $184 \mathrm{c}$.

2. Интродукция некоторых древесных видов растений североамериканской флоры в среднетаежной подзоне Республики Коми / Л.А. Скупченко, О.В. Скроцкая, С.А. Мифтахова, А.Н. Пунегов // Известия Самарского научного центра Российской академии наук. - 2015. - Т. 17. - № 5. C. $208-213$.

3. Мартынов Л.Г. Ритм сезонного развития и зимостойкость европейских видов древесных растений в подзоне средней тайги Республики Коми // Известия Самарского научного центра Российской академии наук. - 2015. - Т. 17. № 5. - C.155-159.

4. Арестова С.В. Мониторинг роста и состояния некоторых видов рода Acer L. в Саратовском Поволжье С.В. Арестова, Е.А. Арестова // Успехи современного естествознания. - 2017. - № 10. - С. 23-28.

5. Strimbeck G.R. Extreme low temperature tolerance in woody plants / G. Richard Strimbeck. Paul G. Schaberg, Carl G. Fossdal, Wolfgang P. Schröde, Trygve D. Kjellsen // Frontiers in Plant Science. 2015. V. 6. Article 884. pp. 1-15. DOI: 10.3389 / fpls.2015.00884.

6. Charra-Vaskou K. Drought and frost resistance of trees a comparison of four species at different sites and altitudes K. Charra-Vaskou, G. Charrier, R. Wortemann, B. Beikircher, H. Cochard, T. Ameglio, S. Mayr // Annals of Forest Science, Springer Verlag/EDP Sciences, 2012, 69 (3), pp. 325-333.

7. Агроклиматические ресурсы Вологодской области. Л.: Гидрометеоиздат, 1972. - 192 с.

8. Андронова М.М. Таксономический состав и систематическая структура дендрофлоры г. Белозерска / М.М. Андронова // Лесной журнал. - 2016. - № 4(352). - С. 54-60.

9. Лысиков А.Б. К вопросу о зимостойкости декоративных культур / А.Б. Лысиков // Актуальные проблемы лесного комплекса. - 2016. - № 44. - С. 39-43.

10. Матвеева Р.Н. Интродукция растений в дендрарии СибГТУ / Р.Н. Матвеева, О.Ф. Буторова, А.Б. Романова. Красноярск: СибГТУ, 2000.- 194 с.

11. Oke T.R. City size and the urban heat island // Atmos. Environ. - 1973. - № 7. - P. 769-779.

12. Shumilov O.I. Urban Heat Island Investigations in Arctic Cities of Northwestern Russia/ O.I. Shumilov, E.A. Kasatkina, A.G. Kanatjev// Journal of Meteorological Research. - 2017. - V. 31. - P. 1161-1162.
13. Бабич Н.А. Зимостойкость и морозоустойчивость интродуцентов / Н.А. Бабич, О.С. Залывская // Лесной вестник. - 2014. - № 1. - С. 105-110.

14. Малаховец П.М. Деревья и кустарники дендросада АГТУ / П.М. Малаховец, В.А. Тисова. - Архангельск: АГТУ, 1999. $-50 \mathrm{c}$.

\section{References}

1. Babich N.A., Karbasnikova E.B., Dolinskaia I.S. Introdutsenty i ekstrazonal'nye vidy $\mathrm{v}$ antropogennoi srede (na primere g.Vologdy) [Introducing and extrazonal species in anthropogenic environment (on the example of Vologda)]. Arhangel'sk, IPTs SAFU, 2012, 184.

2. Skupchenko L.A., Skrotskaia O.V., Miftakhova S.A., Punegov A.N. Introduction of some woody species of north american flora plants in middle taiga subzone in komi republic [Introduktsiia nekotorykh drevesnykh vidov rastenii severoamerikanskoi flory v srednetaezhnoi podzone Respubliki Komi ]. Izvestiia Samarskogo nauchnogo tsentra Rossiiskoi akademii nauk - News of the Samara scientific center of the Russian Academy of Sciences, 2015, vol. 17, no. 5, pp. 208-213.

3. Martynov L.G. Rhythm of seasonal development and winter hardiness of european woody plants species in the middle taiga subzone of komi republic [Ritm sezonnogo razvitiia i zimostoikost' evropeiskikh vidov drevesnykh rastenii $\mathrm{v}$ podzone srednei taigi Respubliki Komi ]. Izvestiia Samarskogo nauchnogo tsentra Rossiiskoi akademii nauk - News of the Samara scientific center of the Russian Academy of Sciences, 2015, vol. 17, no. 5, pp. 155-159.

4. Arestova S.V., Arestova E.A. Growth and condition monitoring of some species of Acer L. genus in Saratov Volga region [Monitoring rosta i sostoianiia nekotorykh vidov roda Acer L. v Saratovskom Povolzh'e]. Uspekhi sovremennogo estestvoznaniia-Advances in Current Natural Sciences, 2017, no. 10, pp. 23-28.

5. Strimbeck G.R. Extreme low temperature tolerance in woody plants . Frontiers in Plant Science, 2015, no. 6, pp. 1-15. DOI: $10.3389 /$ fpls.2015.00884.

6. Charra-Vaskou K. Drought and frost resistance of trees: a comparison of four species at different sites and altitudes. Annals of Forest Science, 2012, no. 69, pp. 325-333.

7. Agroklimaticheskie resursy Vologodskoj oblasti [Agroclimatic resources of Vologda region], Leningrad, Gidrometeoizdat, 1972, pp. 192.

8. Andronova M.M. The taxonomic composition and systematic dendroflora's structure in Belozersk [Taksonomicheskii sostav i sistematicheskaia struktura dendroflory g.Belozerska ]. Lesnoi zhurnal - Forest magazine, 2016, no. 4, pp. 54-60.

9. Lysikov A.B. Issues of the winter hardiness of ornamental crops [K voprosu o zimostoikosti dekorativnykh kul'tur]. Aktual'nye problemy lesnogo kompleksa - Current problems of a forest complex, 2016, no. 44, pp. 39-43.

10. Matveeva R.N., Butorova O.F., Romanova A.B. Introduktsiia rastenii $\mathrm{v}$ dendrarii SibGTU [Introduction of plants in SibGTU arboretum]. Krasnojarsk, SibGTU, 2000, 194.

11. Oke T.R. City size and the urban heat island. Atmospheric Environment, 1973, no. 7, pp. 769-779.

12. Shumilov O.I. Urban Heat Island Investigations in Arctic Cities of Northwestern Russia. Journal of Meteorological Research, 2017, no. 31, pp. 1161-1162.

13. Babich N.A., Zalyvskaia O.S. Winter hardiness and frost resistance of exotic species [Zimostoikost' i morozoustoichivost' introdutsentov]. Lesnoi zhurnal - Forest magazine, 2014, no. 1, pp. 105-110.

14. Malakhovets P.M., Tisova V.A. Derev'ia i kustarniki dendrosada AGTU [Trees and shrubs of ASTU arboretum]. Krasnojarsk, AGTU, 1999, 50. 